\title{
AN EXPERIMENTAL STUDY ON MECHANICAL PROPERTIES OF CONCRETE-FILLED STEEL TUBE (CFST) KEY-CONNECTED PREFABRICATED WALL AND COLUMN
}

\author{
Qian $\mathrm{Wu}^{1,2}$, Guo-Chang $\mathrm{Li}^{2,}{ }^{*}$, Ming $\mathrm{Li}^{2}$ and Yuan-Wei Luo ${ }^{1,2}$ \\ ${ }^{1}$ School of Civil Engineering, Dalian University of Technology, Dalian, Liaoning, 116024, china \\ ${ }^{2}$ School of Civil Engineering, Shenyang Jianzhu University, Shenyang, Liaoning, 110168, china \\ *(Corresponding author: E-mail:liguochang0604@sina.com)
}

\section{A B S T RA C T}

The prefabricated structures have the advantages of high construction speed, energy efficiency, environmental friendliness, and low labor demand. At present, the connection of fabricated concrete structural components mainly relies on connecting the stressed steel bars of the prefabricated components using a variety of methods, and then casting concrete or grout at the joints. This requires a large quantity of wet work, and most studies on this topic focused on frame structures and shear wall structures. The research on frame-shear wall structures is still rare. To fill this gap, a new type of connecting prefabricated shear wall and prefabricated frame column in the assembled frame-shear structure by using concrete-filled steel tubs (CFST) keys is proposed with experimental study. This paper analyzes the differences in the mechanical properties and the failure modes of three kinds of structures, i.e. the wall and column connected by CFST keys, the wall and column connected by the CFST keys with concrete block placed between them, and the wall and column connected by the cast-in-place method. This paper also investigates the mechanical properties and failure modes of the first kind of structure when the failure of shear wall is caused by the CFST keys. The test results show that the CFST keys with the reinforced concrete block placed between them are superior to the cast-in-place structures in terms of wall-column connection mode, and the bearing capacity and ductility of the structure, while sharing similar initial stiffness of the structure.The CFST keys connection mode shows engineering feasibility and good seismic performance. When designing this type of connection, the strength of the CFST keys should be moderately controlled. If the strength level is too high, the shear resistance of the overall structure will decrease.

\section{A R T I C L E H I S T O R Y}

$\begin{array}{ll}\text { Received: } & \text { 30 September } 2019 \\ \text { Revised: } & \text { 10 April 2020 } \\ \text { Accepted: } & \text { 18 April } 2020\end{array}$

\section{K E Y W O R D S}

Concrete-filled steel tube;

frame column;

shear wall;

Prefabricate

Frame-shear wall structure

\section{Introduction}

The prefabricated concrete structure has the advantages of high construction speed, good energy efficiency and environmental friendliness, and low labor demand. It has become a topic of common concern for civil engineers in various countries. Japan, the United States, France and other countries have given continuous attention to the prefabricated concrete structure. Among them, in Japan, 9 million prefabricated houses were built during the period 1963 to 2014 and about 150,000 houses were built each year in the last few years. Since the 1950s, the development of prefabricated buildings has started in the US, where a typical movable house can be completed by prefabrication (Yuan et al.[1], Si et al.[2]). In China, a large number of prefabricated buildings were made in the 1970s and 1980s. However, due to the limited level of science and technology at that time, there were engineering quality problems in these buildings, which were gradually replaced by cast-in-place structures. With the advancement of science and technology in the past ten years, rapid progress was witnessed in the development of prefabricated concrete structures in China, and a large number of such structures have been built throughout the country, achieving remarkable economic and social benefits. This fully demonstrates that the prefabricated buildings are one of the important development directions of the world's future buildings.

The development of prefabricated reinforced concrete structures is based on the cast-in-place ones, which has three important types: frame structure, shear wall structure, and frame-shear wall structure. The key technical issue of the fabricated concrete structures is to study how to realize the splitting and connection of the above-mentioned structures, and to ensure that the performance of the prefabricated structures is at least as good as that of the cast-in-place ones. In order to achieve this goal, scholars of various countries carried out a number of theoretical and experimental research. The research on the fabricated frame structure started earlier and has yielded numerous connection methods, of which the beam and column were connected initially by extending the steel bars from the end of the prefabricated members or by the bracket of the column (Restrepo et al. [3]). New development included the form of the main ribs of the beam and column connected by the sleeve grouting method ( $\mathrm{Li}$ et al. [4], $\mathrm{Li}$ et al.[5]) and the connection form using prestressed or high-strength steel bars (Alcocer et al.[6],Guan et al.[7], Zhao et al.[8]), both of which have achieved good results. The research on the fabricated shear wall structure started later (Lu et al.[9], Chen et al.[10]), but also produced a number of research findings. For example, different types of shear walls have been studied, including linear type, I-shaped, L-typed, and T-shaped. Several studies focused on the influence on the seismic behavior of these shear walls exerted by the following factors: the length of the splicing zone, the length of the ribs, the material of the splicing zone, and the form of the splicing zone(Sun et al.[11], Song et al.[12], LU et al.[13], JGJ101-96[14], Smith et al.[15], Pekau et al.[16], Soudki et al.[17], LI et al.[18], Soudki et al.[19]). Nevertheless, there are few studies on the prefabricated frame-shear structure. Compared with the frame and shear wall structure, the assembled frame-shear structure requires more research on the wall-to-column connection techniques and wall-to-beam connection techniques.

To this end, our research team proposed straight rib joint, straight rib U-shaped lap joint, U-shaped rib lap joint, and chain buckle lap joint to be used for the wall-column or beam-wall connection. The direct shear test and the quasi-static test with two-layer plane structure were carried out. The results showed that the mechanical properties of the latter two are better (Yuan.[1], Si.[2], Wang.[20], Gao.[21], Liang.[22]). This method is suitable for a single-storey construction condition where the wall and column are large. When the wall and column are small in a single-storey building, the wall, column and beam can also be prefabricated into a unit, and then assembled directly in a similar way to the frame and shear wall structure. Research has shown that this method can also be achieved satisfactory effects (Mo, et al.[23], Ma, et al.[24]).

As mentioned above, while various connection schemes have been proposed in the research and development of the assembly technology of the prefabricated concrete components, these schemes mainly use different methods to connect the stressed steel bars of the prefabricated components and then cast concrete or grout at the joints to realize the prefabrication. The connection between the components requires relatively heavy wet work at the joints and the construction quality is difficult to control (Wu et al.[25] and [26], Bin et al.[27], Ming et al.[28]). Therefore, some researchers have proposed the use of steel or steel tube concrete to join prefabricated concrete components, in order to reduce the amount of wet work and further increase the degree of industrialization. They also predicted that the form of the combined structure would likely become an ultimately accepted form in the development of prefabricated buildings. Based on this line of research, our research team proposed a new scheme of connecting prefabricated shear wall and prefabricated frame column in the assembled frame-shear structure with CFST keys, and analyzed its feasibility by finite element simulation method (Gao.[21], Liang.[22]). We continue to conduct experimental research in this paper. These findings will drive the application of composite structural 
components in fabricated concrete structures.

\section{Structure of wall and column connected with CFST keys}

The components and assembly structure of the CFST key-connected wall and column are shown in Fig.1. Fig.1 (a) is the embedded part, which is composed of anchor steel plate, bottom steel plate and shear steel plate. Fig.1 (b) is CFST key, and Fig.1(c) is precast reinforced concrete block (the internal stirrup is 3A8@100, the internal longitudinal reinforcement is $4 C 18$. andindicate the yield strength of the bars is $300 \mathrm{Mpa}$ and $400 \mathrm{Mpa}$, respectively (GB50017-2017[27]). Fig.1(d) is a split diagram of the embedded part. Fig.1(e) is a schematicdiagramof the structureof the CFST key-connected wall and column.

The construction sequence is as follows: Firstly, the prefabricated wall and the prefabricated column are placed in predeterminateposition. After the CFST keys are placed between the prefabricated column and the prefabricated wall, the two ends are welded on the bottom steel plate of the embedded part in the prefabricated wall and the prefabricated column. Lastly, the reinforced concrete block is placed between the CFST keys. The gapsamong the CFST keys, the reinforced concrete block, the prefabricated wall, and the prefabricated column are filled with grout. In this process, to meet the installation requirements, the height of the CFST keys should be slightly smaller than the spacing of the shear-resistant steel plate of the embedded part; and the length of the CFST keys should be slightly smaller than the distance between the fabricated column and the fabricated wall. The construction error of the part can be filled by the weld; The size of the reinforced concrete block should be slightly smaller than the hole between the CFST keys and the prefabricated column and the prefabricated wall, and the gap can be filled with the grout.

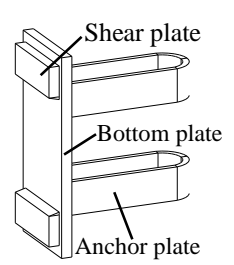

(a)Embeddedpart

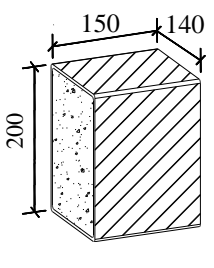

(b) CFST key

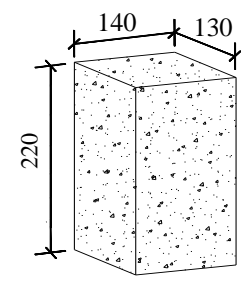

(c) Reinforced concrete block

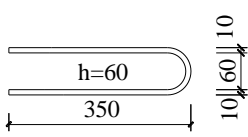

Anchor plate

Shear plateBottom plate

(d) Embedded parts split diagram

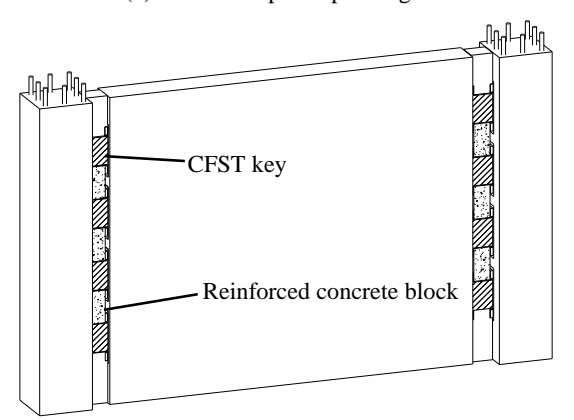

(e) Three-dimensional diagram of the structure with CFST key-connected wall and column

Fig. 1 Three-dimensional diagram of components and structure of the CFST key-connected wall and column

\section{Experimental program}

\subsection{Design and fabrication of specimen}

In the event of horizontal earthquake action, the prefabricated frame column and the prefabricated shear wall will move against each other. When this happens, the CFST keys will play a role of deformation coordination, bearing the shear force resulted from the movements between them. To study the effect of transmitted shear force, we conducted a two-stage experimental study. In the first stage, the failure of the CFST keys was controlled. The analysis was focused on the differences in the mechanical properties and the failure modes among three kinds of structures, i.e., the wall and column are connected by the CFST keys, the wall and column are connected by the CFST keys with concrete block placed between them, and the wall and column are connected by the cast-in-place method. We attempted to identify a wall-column connection scheme that meets the requirements. In the second stage, a condition was controlled to make sure that no or only minor failure of the CFST keys occur, while the connected wall failed.The focus was on the mechanical properties and failure modes of the shear wall caused by the CFST keys.

To complete the analysis of the first stage, we designed specimens S1, S2, and S3. In order to ensure the failure of the CFST keys, frame column components were designed at the two ends of the CFST keys of the specimens.The geometry and reinforcement of each specimen are shown in Fig.2. Specimen S1 was not equipped with reinforced concrete blocks between the CFST keys; Specimen S2 contained a reinforced concrete block between the CFST keys. Specimens S1 and S2 had the same reinforcement. Specimen S3 was a cast-in-place specimen with the connection area being a shear wall. The sizes of shear steel plates used in Specimens S1 and S2 were designed according to the shear force transmitted by the three-sided welded seam of the shear steel plate and the shear capacity of the CFST keys. The size of the CFST keys was determined based on the relevant literature(GAO.[21]). The wall thickness of the steel tube is $4 \mathrm{~mm}$. The dimensions of the embedded parts, CFST keys, and reinforced concrete blocks are shown in Fig.1.

To complete the analysis of the second stage, specimen S4 was designed. One end of the CFST keys of the specimen was connected to the frame column, and the other end was connected to the shear wall. In order to ensure that no damage or only minor damage to the CFST keys when the specimen wastested, the wall thickness of the steel tube was increased to $8 \mathrm{~mm}$. The geometrical dimensions and reinforcement of the specimen are shown in Fig.3. Specimen S4 shared some identical properties with specimens S1 to S3 in the dimensions of the CFST keys, the embedded part, the steel bars for the beam and column, the beam, and the column. The strength of concrete and the steel bar and the steel plate were also the same with those specimens. The steel strain gauge arrangement is shown in Fig.3(a), which uses $\operatorname{Si}(i=1,2,3, \ldots)$ to indicate the strain gauge number of the steel.

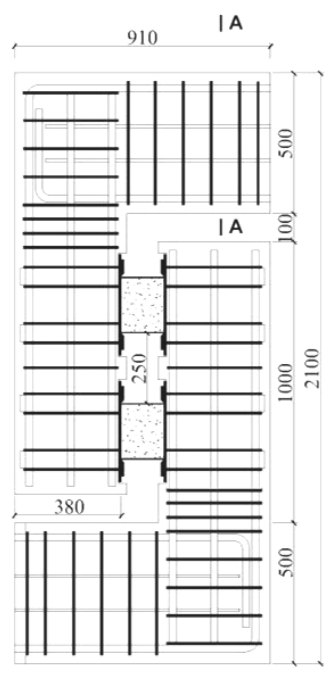

(a) Specimens S1 and S2

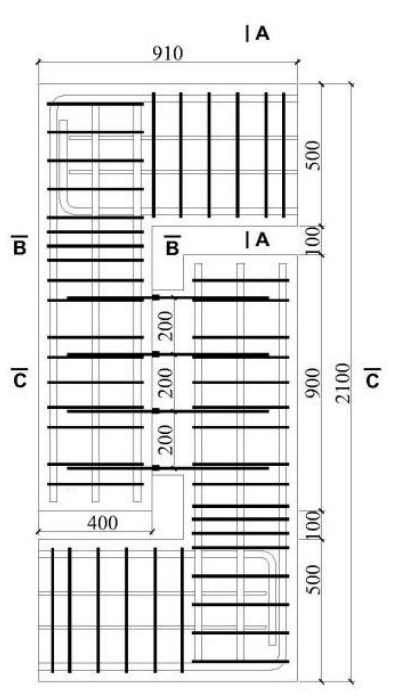

(b) Specimen S3

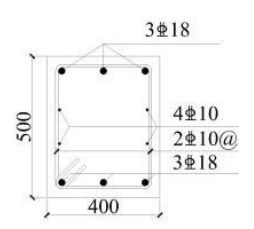

A-A

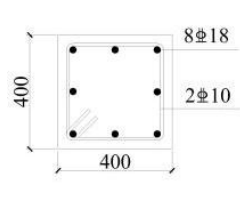

B-B

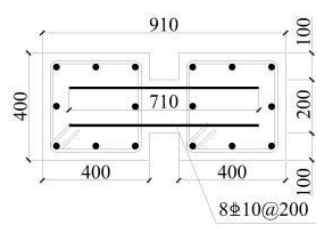

C-C
Fig. 2 Geometrical dimensions and reinforcement diagram of specimens S1, S2and S3 

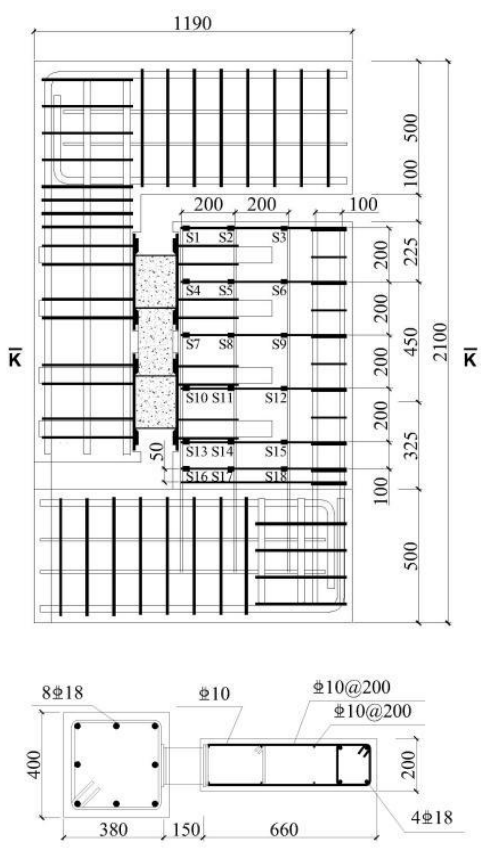

D-D

Fig. 3 Geometrical dimensions, reinforcement, and steel strain gauge arrangement of specimen $\mathrm{S} 4$

\subsection{Materials mechanical properties}

In the test, Chinese grade Q235B structural steel was used for all steel members (GB50017-2017 [29]), and Chinese grade C40structural concretewas used for all concrete members (GB50010-2010 [30]). Standard coupons were cut from each steel member and tested. The material properties of steel and concrete are listed in Table 1 , where $\varepsilon_{\mathrm{y}}, f_{\mathrm{y}}, f_{\mathrm{u}}, E_{\mathrm{s}}$ are steel yield strain, yield strength, tensile strength and elastic modulus respectively. Casting of $150 \times 150 \times 150 \mathrm{~mm}$ cubes for concrete strength $\left(f_{\text {ck }}\right)$ test and $150 \times 150 \times 300 \mathrm{~mm}$ cylinder for concrete Young's modulus $\left(E_{\mathrm{c}}\right)$ were carried out at the same time. They were cured in similar conditions as the specimen.

Table 1

Material mechanical properties of steel bar and concrete

\begin{tabular}{cccccc}
\hline Material & $\begin{array}{c}E_{\mathrm{s}} / E_{\mathrm{c}} \\
\left(\mathrm{N} / \mathrm{mm}^{2}\right)\end{array}$ & $\begin{array}{c}E_{\mathrm{y}} \\
(\mu \varepsilon)\end{array}$ & $\begin{array}{c}f_{\mathrm{y}} \\
(\mathrm{MPa})\end{array}$ & $\begin{array}{c}f_{\mathrm{u}} \\
(\mathrm{MPa})\end{array}$ & $\begin{array}{c}f_{\mathrm{ck}} \\
(\mathrm{MPa})\end{array}$ \\
\hline Steel bar (A8) & $1.4 \times 10^{5}$ & 3100 & 434 & 584 & - \\
Steel bar (C10) & $2.2 \times 10^{5}$ & 2400 & 528 & 604 & - \\
Steel bar (C14) & $1.7 \times 10^{5}$ & 2335 & 397 & 563 & - \\
Steel plate(t=4) & $2.1 \times 10^{5}$ & 1304 & 274 & 352 & - \\
Steel plate ( $\mathrm{t}=8)$ & $2.2 \times 10^{5}$ & 1686 & 371 & 501 & - \\
Steelplate $(\mathrm{t}=10)$ & $2.2 \times 10^{5}$ & 1695 & 362 & 489 & - \\
Concrete & $3.4 \times 10^{4}$ & - & - & - & 42 \\
\hline
\end{tabular}

\subsection{Experimental setup and loading procedure}

Fig. 4 shows the test loading device, the displacement gauge, and strain gauge layout for specimens S1 to S3. Fig.4(a) shows the $10000 \mathrm{kN}$ largescale mufti-functional structural testing machine system (WAW-J12000J); Fig.4(b) and Fig.4(c) show the displacement gauge and strain gauge layout of specimens S1, S2and S3, respectively. The top of the specimen was provided with a loading steel plate $(400 \mathrm{~mm} \times 300 \mathrm{~mm} \times 40 \mathrm{~mm})$. To prevent local pressure damage, a layer of fine sand was placed to the contact area between the loading steel plate and the specimen. The bottom of the specimen was placed directly on the test bench, and blocks were arranged on both sides. The two ends of the block were tightly attached to the steel beam anchored on the test bench to prevent the specimen from moving laterally. A jack was applied with a vertical load in contact with the loading steel plate, and the loading force center passes through the symmetry axis of the specimen. Strain gauges (Y1 to Y8) were arranged at the upper and lower surface ends of specimens S1, S2and the strain gauge rosettes ( $\mathrm{H} 1$ and $\mathrm{H} 2$ ) were arranged at the center of the side of the steel tube, as shown in Fig.4(b). Strain gauges (Y1 to Y8) were placed at the point where the column is connected with the horizontal steel bar on the wall for specimen S3, as shown in Fig.4(c). Horizontal displacement meters (W1 and W2) were placed on the side of specimens S1, S2and S3 to monitor whether the specimen moves horizontally. A vertical displacement meter (W3) was placed on the side of the specimen to monitor the vertical displacement of the specimen, as shown in Fig.4(b) and Fig.4(c). In addition, vertical displacement information was also collected by the test machine system.

Loading was performed by graded loading with each level set at $150 \mathrm{kN}$, each stage held for 1 to 2 minutes, and the loading speed controlled at 0.5 $\mathrm{mm} / \mathrm{min}(\mathrm{GB} / \mathrm{T}$ 50152-2012 [31]).

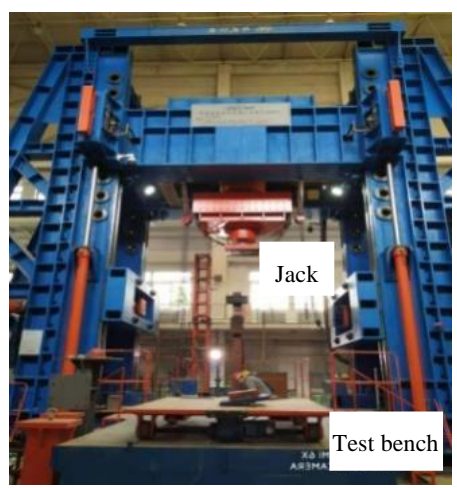

(a)Testing machine system

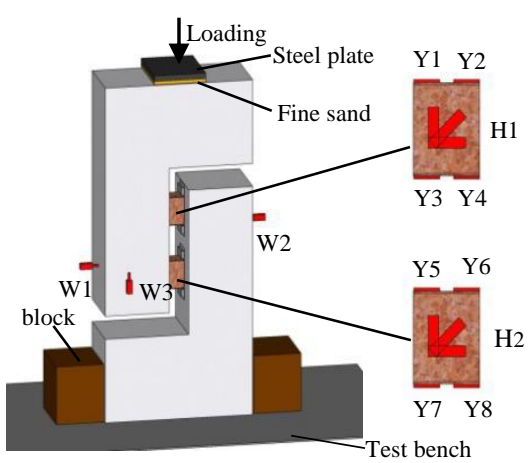

(b) Displacement gauge and strain gauge layout for specimens $\mathrm{S} 1$ and $\mathrm{S} 2$

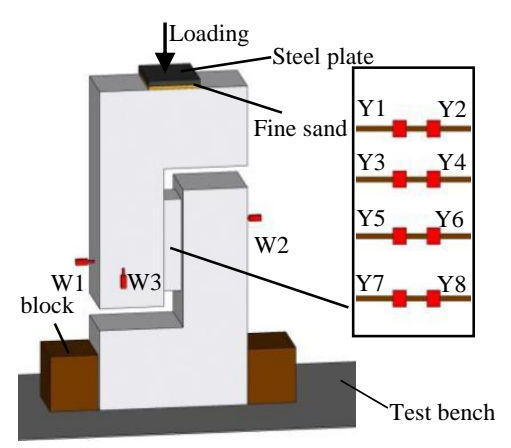

(c) Displacement gauge and strain gauge layout for specimen $\mathrm{S} 3$

Fig. 4 Test loading device, displacement gaugeandstrain gauge layout

When specimen S2 was tested by the above device, the junction area between the column end and the beam was broken because the reinforced concrete block was arranged between CFST keys of the specimen S2 and the shear bearing capacity was high. The first test failed, as shown in Fig.5(a). Therefore, the specimen was re-reinforced. The cracked concrete was removed and the grout was used for filling, as shown in Fig.5(b). To avoid the damage of this junction area, a reinforced test device was designed, as shown in Fig.6. That is, a steel beam was added on the side of the column; One end of the steel beam was fixed by the end steel plate and the tie rod, and the other end was fixed by the L-shaped fastener. One end of the fastener was connected to one side of the column by a thick steel plate, and the other end was connected to the end beam by a tie rod and a nut. With this reinforcing device, the test of the specimen S2 was successfully completed. 


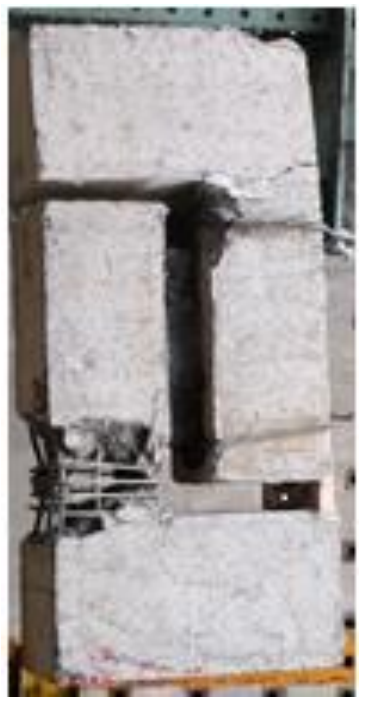

(a)Failed specimen

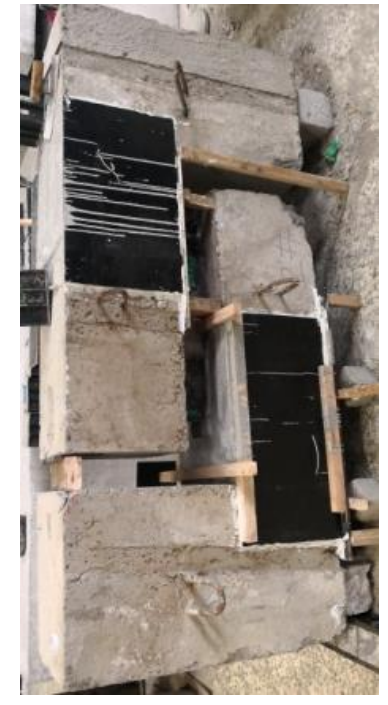

(b)Reinforcedspecimen
Fig. 5 Failed specimen and reinforced specimen

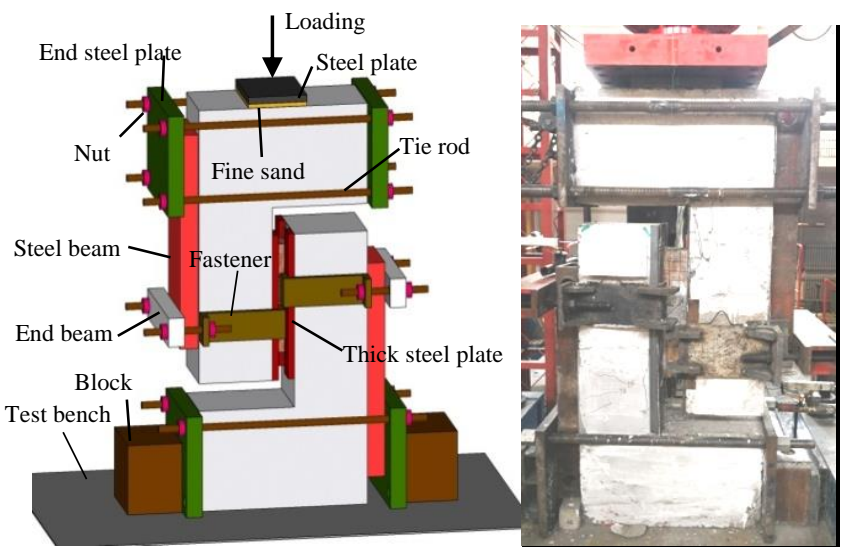

Fig. 6 Reinforced specimen and test device

In order to ensure that the beam-column junction area does not break which leads to the failure of a test, a column reinforcement method was applied directly to the loading device for specimen S4, as shown in Fig. 6. The positions of the displacement gauges (W1, W2, W3, and W4), the strain gauges (G1 to G8), and the strain gauge rosettes (GH1 and GH2) of the CFST keys are also indicated in Fig.7. Specimen S4 was loaded with the center of the force through the center of the CFST keys.

\section{Experimental results and discussions}

\subsection{Comparison of load-displacement curves}

Fig.8 is a load-vertical displacement curve of each specimen. For the convenience of analysis, the following variables were calculated: The initial stiffness $E_{0}$ of each specimen (ratio of vertical load to the according displacement in the elastic phase), yield load $P_{\mathrm{y}}$ (calculated with the "universal yield bending moment method"), maximum load $P_{\max }$, ultimate load $P_{\mathrm{u}}$ (85\% of maximum load), and the corresponding displacement ductility coefficient $\mu$ (the ratio of the ultimate load to the corresponding displacement of the yield load) (Bin etal.[27], Ming etal.[28], GB50017-2017 [29], Li et al .[32]). The results are as shown in Table 2 .

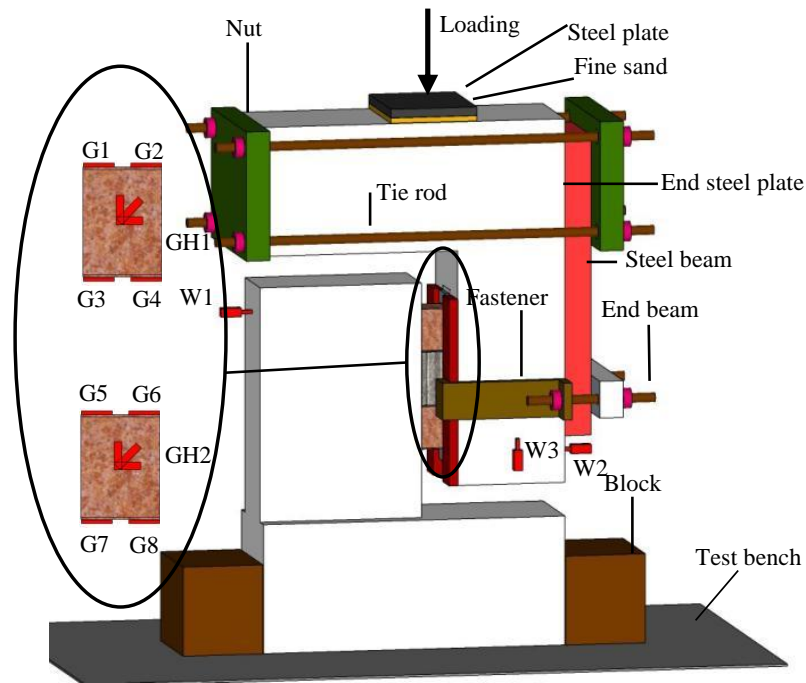

(a) Displacement gauge and strain gauge layout for specimen S4

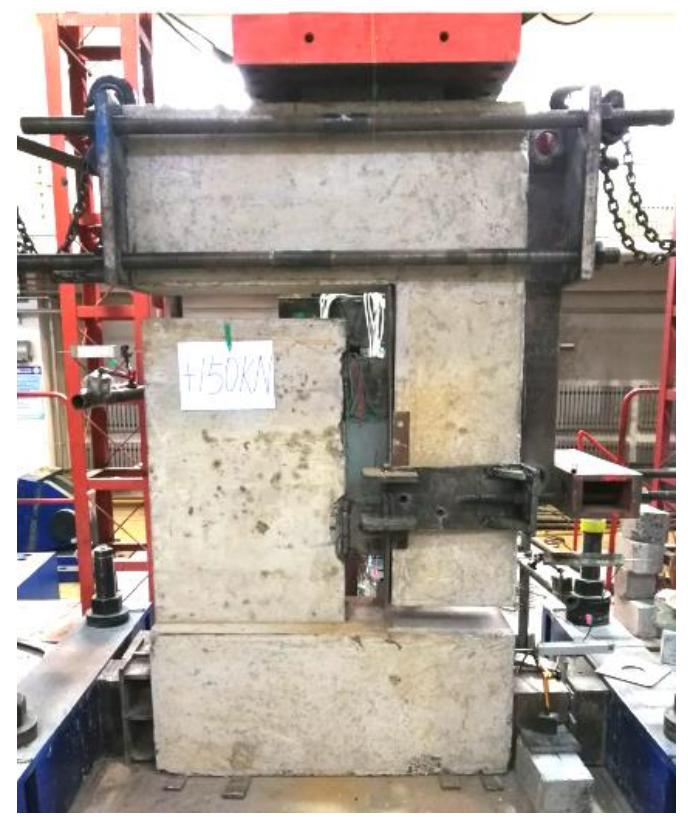

(b) SpecimenS4 and test loading device

Fig. 7 Displacement gauge and strain gauge layout for specimen S4

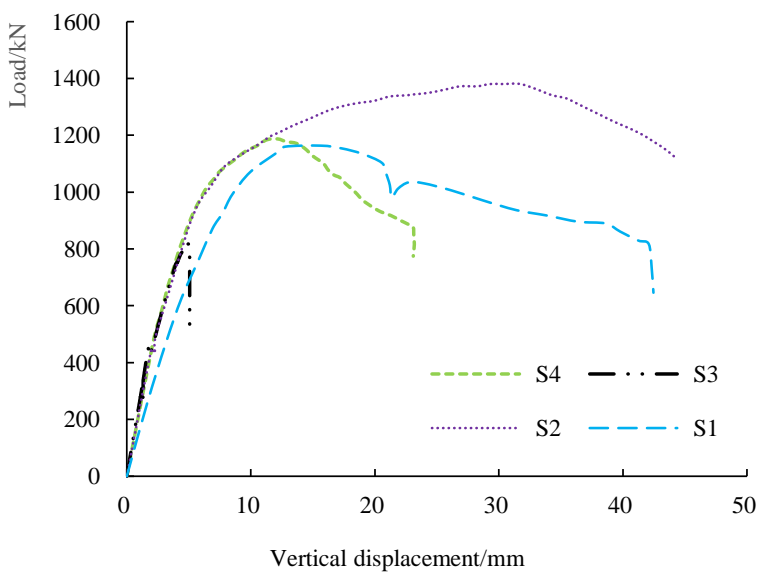

Fig. 8 Load-vertical displacement curves of each specimen 
Table 2

Material properties of each specimen

\begin{tabular}{cccccc}
\hline Specimennumber & $P_{\mathrm{y}} / \mathrm{kN}$ & $P_{\max } / \mathrm{kN}$ & $P_{\mathrm{u}} / \mathrm{kN}$ & $\mu$ & $E_{0} /(\mathrm{kN} / \mathrm{mm})$ \\
\hline S1 & 881 & 1163 & 988 & 3.8 & 169 \\
S2 & 980 & 1381 & 1173 & 6.9 & 225 \\
S3 & 666 & 822 & 698 & 1.5 & 237 \\
S4 & 910 & 1180 & 1003 & 3.09 & 207 \\
\hline
\end{tabular}

Note: $P_{\mathrm{y}}$-yield load; $P_{\max }-$ maximum load; $P_{\mathrm{u}}$-ultimate load; $\mu$ - displacement ductility coefficient; $E_{0}-$-initial stiffness

It can be seen from Fig. 8 and Table 2 that, compared with specimen S3, specimens S1 and S2 had better elasticity (before yielding load), higher elastoplasticity (between yield load and maximum load) and longer plastic section (after maximum load). Specimen S3 only showed noticeable elastic segments, while the coefficients of ductility of specimens S1 and S2 was $156 \%$ and $364 \%$ higher than that of specimen S3, respectively. In the elastic section, the initial stiffness of specimen S1 was $38 \%$ lower than that of specimen S3, and the initial stiffness of specimen S2 and specimen S3 was close. In the elastoplastic stage, the yield bearing capacities of specimens S1 and S2 were $32 \%$ and $42 \%$ higher than that of specimen S3, respectively, and their maximum bearing capacities were $42 \%$ and $68 \%$ higher, respectively. In the descending section, the ultimate bearing capacities of specimensS1 and S2 were $42 \%$ and $68 \%$ higher than that of specimen S3, respectively. The results indicate that the connection mode with and without reinforced concrete block was much better than cast-in-place structure in terms of bearing capacity and ductility. However, the initial stiffness of the latter is low. Therefore, the former has engineering feasibility.

Compared with specimen S2, specimen S4 also showed noticeable elasticity, elastoplasticity, and descending sections. Nevertheless, its descending section started earlier and its ductility coefficient was 50\% lower than that specimen S2. In the elastic section, these two almost overlapped and their levels of initial stiffness were almost identical. In the elastoplastic section, specimen S4's yield bearing capacity was $7 \%$ lower than that of specimen S2, and the maximum bearing capacity was $15 \%$ lower. In thedescending section, specimen S4's ultimate bearing capacity was $15 \%$ lower than that of specimen S2.

Overall, the results show that for the connection of the CFST keys to the column and wall, when the CFST keys was designed too strong relative to the wall, damage will be transferred to the wall, causing a decrease of the shear resistance and ductility of the overall structure. Therefore, when designing this type of connection, we should control the strength of the CFST keys.

\subsection{Analysis of the failure process of the specimen}

In order to analyze the failure process of each specimen, we took photographs of the concerned areas of each specimen at the following load: load $P=150 \mathrm{kN}$ (representing elastic section), yielding load $P_{\mathrm{y}}$, maximum load $P_{\max }$, and ultimate load $P_{\mathrm{u}}$

\subsubsection{Analysis of the failure process of specimens $S 1, S 2$, and $S 3$}

Fig.9 is a photograph of the concerned areas of specimens S1 to S3 at different load. It can be seen from the figure that for specimen S1, when yield occurred with increased load, the CFST keys did not deform significantly, and they were inclined at the maximum load. However, the steel tube itself did not show obvious buckling. At the ultimate load, the bottom steel plate at the right lower corner of the CFST keys showed obvious local buckling. As for specimen S2, the failure stage was obvious. Before the yield load, the reinforced concrete block showed no obvious oblique crack. With yield occurred with increased load, oblique cracks occurred in the reinforced concrete block, and there was no obvious local buckling in the CFST keys. During the ultimate load, the buckling deformation occurred on the surface of the CFST keys, and the through crack occurred in the oblique direction of the reinforced concrete block. For specimen S3, multiple cracks appeared when yield occurred with increased load and cracks spread over the entire concrete surface at the maximum load and the ultimate load.

It can be seen from the failure processes of specimens S2 and S1 that the reinforced concrete blocks and the CFST keys were mutually restrained. The former can effectively prevent the local buckling, and the latter can prevent the former from being damaged after a through crack happened. Therefore, with the reinforced concrete blocks placed, the initial stiffness, bearing capacity, and ductility of the overall structure were significantly improved. Meanwhile, the results also show that the overall structural failure stage of the reinforced concrete block was obvious. In the elastic stage, the reinforced concrete block and the CFST keys were intact, which can meet the seismic fortification target of "no damage under small earthquakes" After reaching the yield load, the reinforced concrete block cracked first, which reducedthe structural rigidity and enabled better ductility of the overall structure. This characteristic can help better meet the seismic fortification target of "no collapse in major earthquakes." It can be seen from the failure processes of specimens S2 and S3 that after yield occurred with increased load, specimen S3 had a faster breaking speed, and specimen S2 had slower destruction.This shows that the CFST keys connection method with reinforced concrete locks placed between the keys enhanced the seismic performance of the overall structure.

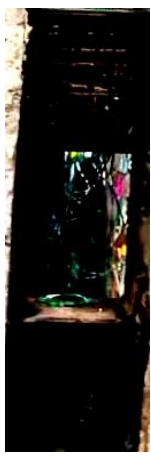

$P=150 \mathrm{kN}$

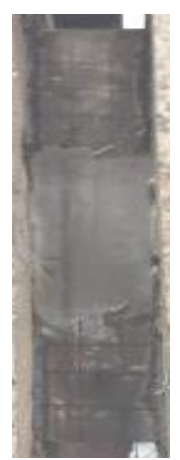

$P=150 \mathrm{kN}$

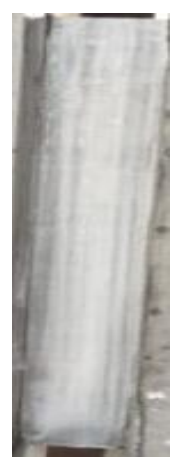

$P=150 \mathrm{kN}$

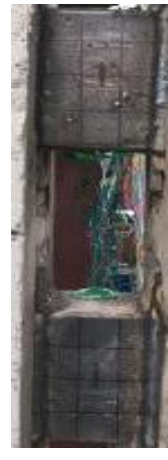

$P_{\mathrm{y}}=881 \mathrm{kN}$$$
\text { (a) Failur }
$$

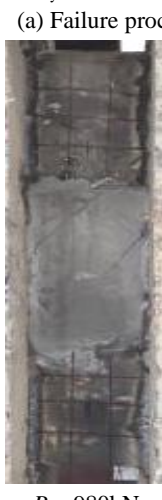

$P \mathrm{y}=980 \mathrm{kN}$

(b) Failure proces

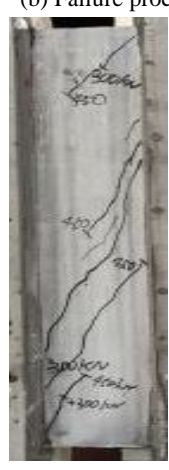

$P_{\mathrm{y}}=666 \mathrm{kN}$

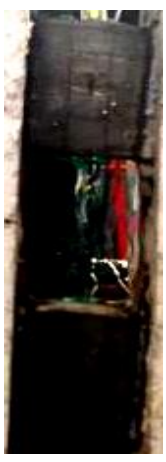

$P_{\max }=1163 \mathrm{kN}$

of specimen $\mathrm{S} 1$

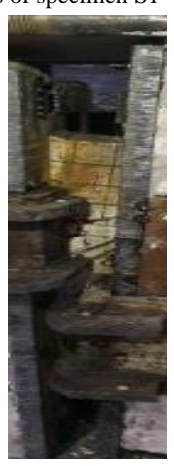

$P_{\max }=1381 \mathrm{kN}$

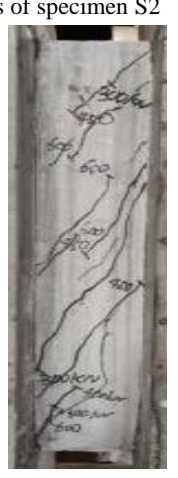

$P_{\max }=822 \mathrm{kN}$
$P_{\mathrm{u}}=988 \mathrm{kN}$

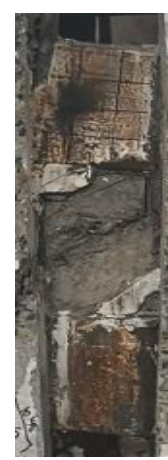

$P_{\mathrm{u}}=1173 \mathrm{kN}$

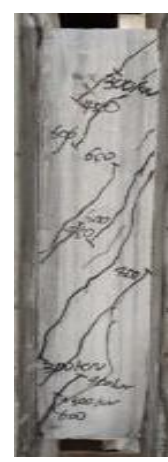

$P_{\mathrm{u}}=698 \mathrm{kN}$

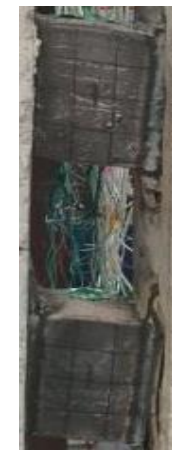

(c) Failure process of specimen $\mathrm{S} 3$

Fig. 9 Failure of the concerned areas in specimens S1 to S3 at different loading stages

\subsubsection{Analysis of the failure process of specimen $S 4$}

Fig.10 is a photograph of the concerned area of specimen S4 at different stages of loading. As can be seen from Fig.10, the failure order of the structural part of specimen S4 was the same as that of specimen S2. That is, the reinforced concrete block cracked first, and then the overall structure failed. The difference is the crack form of the two. Specimen S4 had a vertical crack first and then a diagonal crack, whereas specimen S2 had only a diagonal crack. This is mainly because the columns at both ends of the CFST keys of specimen S2 experienced a relatively larger horizontal displacement, and the force of CFST keys on the reinforced concrete block had large eccentricity.

As shown in Fig.10(c), when specimen S4 reached the maximum load, the oblique crack of the reinforced concrete block further developed and spread over the surface of the entire reinforced concrete block. A large number of the cracks were the cross-sloping ones in terms of crack form. Specimen S2 only showed a small number of oblique cracks on the reinforced concrete blocks. At the same time, it can be seen that the shape of the steel tube of specimen S4 
was hardly changed, and the degree of damage was much lower than that of specimen S2. This shows that after the CFST key was reinforced with respect to the wall, the efforts of reducing the damage of the CFST key itself would cause more serious damages to the reinforced concrete block. This is due to the fact that the deformation coordination ability of the two was poor. As shown in Fig.10(d), when the ultimate load was applied to specimen S4, the number of cracks in the reinforced concrete block and the appearance of the CFST key did not change much compared with the outcome with the maximum load, indicating that the damages at this stage were mainly on the walls.

With regard to the wall damage, under the yield load, a number of oblique cracks appeared in the upper rightpart of the wall and shear failure occurred; horizontal cracks appeared in the lower left part of the wall and bending failure occurred. As the load continued to increase to the maximum load, the number of oblique cracks and the curved cracks further increased and these cracks became longer; vertical cracks appeared in the lower right corner of the wall, and compression damage occurred. When the load decreased to the ultimate load, the reverse oblique crack appeared in the lower right corner of the wall and shear failure occurred. Meanwhile, the cracks spread over almost the entire wall and the wall was fully damaged, showing a good ductility.

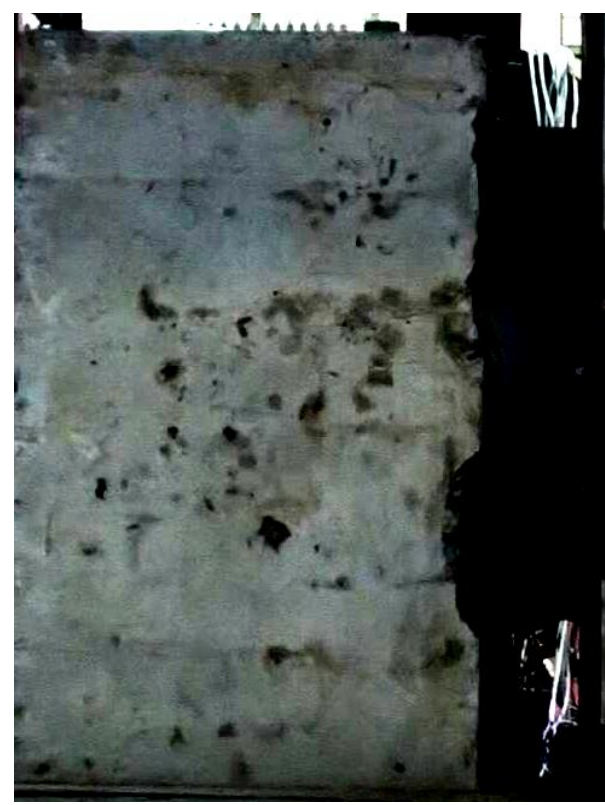

(a) $\mathrm{P}=150 \mathrm{kN}$

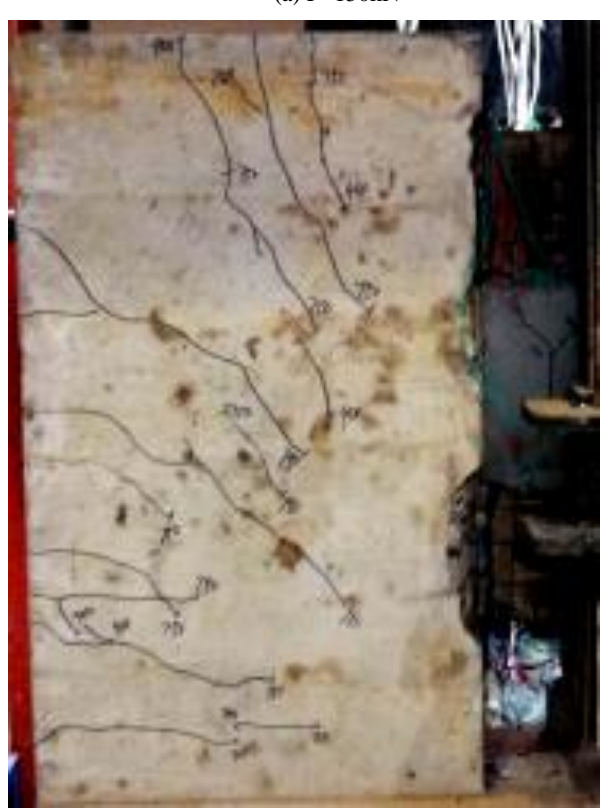

(b) $\mathrm{Py}=910 \mathrm{kN}$

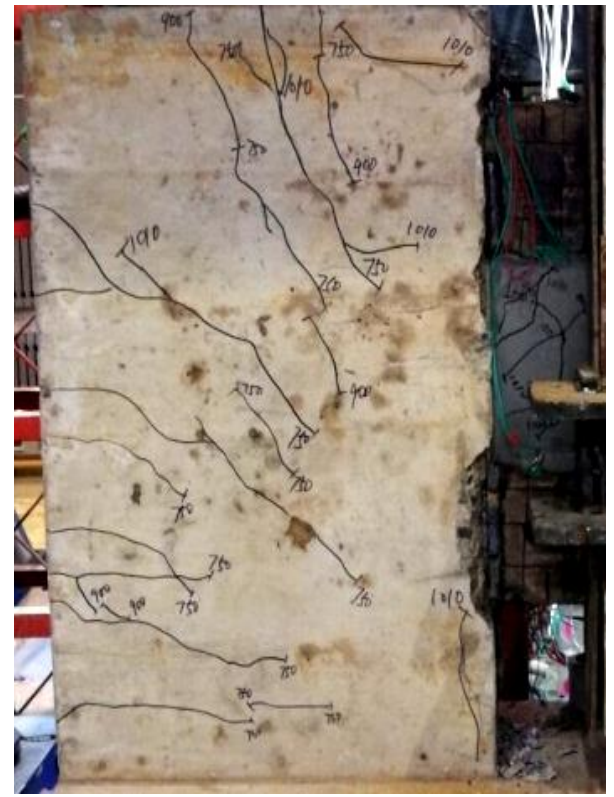

(c) $P_{\max }=1180 \mathrm{kN}$

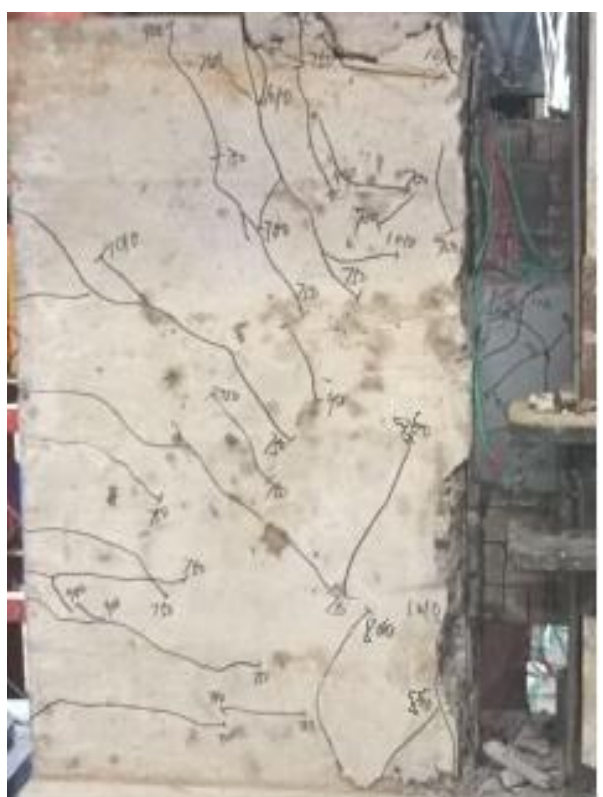

(d) $P_{\mathrm{u}}=1003 \mathrm{kN}$

Fig. 10 Photograph of the study area of specimen S4 at different loading stages

\subsection{Analysis of strain or stress of the steel tubes and steel bars}

4.3.1. Analysis of strain stress of steel tubes and steel bars of specimens $S 1$ to S3

In order to analyze the yielding condition of the steel tubes of the CFST keys, the load-strain relationship curves of strain gauges laid at the position (Y1 Y8) shown in Fig.2 for specimens S1 to S3 are extracted and shown in Fig.11. The y-axis is for the vertical load applied to the specimen and the $\mathrm{x}$-axis shows the strain measured by the strain gauge. It can be seen from Fig.11(a) and Fig.11(b) that before specimens S1 and S2 reached the yield load, the end portion of the steel tube of the CFST key had almost yielded, indicating that the strength of the steel tube is fully exerted. It can also be seen that the distribution of the strain was not completely symmetrical around the load axis, which is mainly due to the incomplete symmetry in the geometrical dimensions of the specimens, materials, and so on. It can be seen from Fig.11(c) that after the concrete reached the cracking load $(402 \mathrm{kN})$ and when the load continued to rise to about $450 \mathrm{kN}$, the steel bars yielded almost simultaneously This indicates that the shear strength of the specimens decreased sharply after the concrete cracked, and the shear enhancement effect of the steel bars was not obvious. 


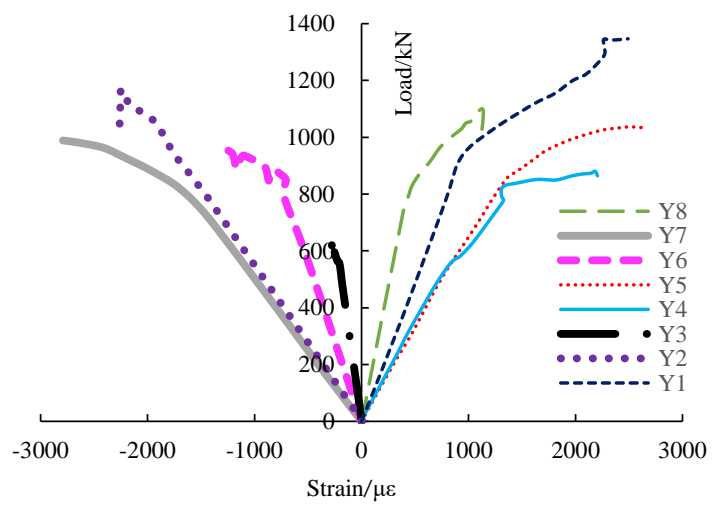

(a) Load-strain curves ofspecimen $\mathrm{S} 1$

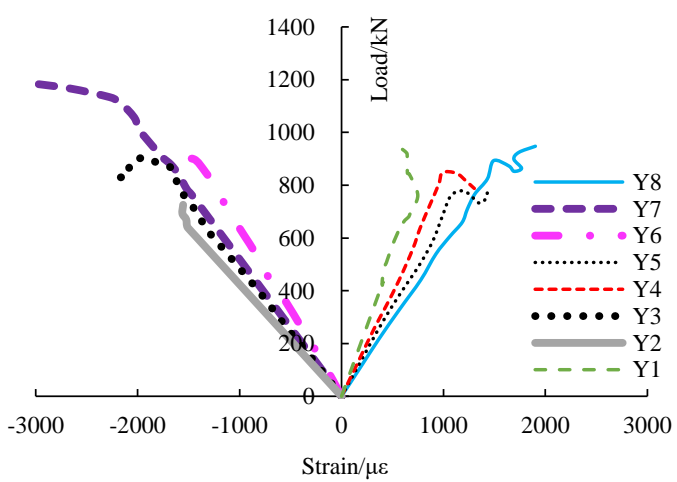

(b) Load-strain curves ofspecimen S2

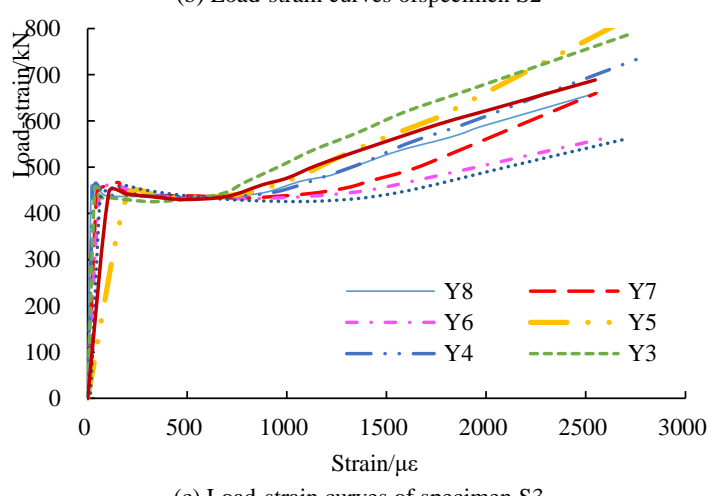

(c) Load-strain curves of specimen $\mathrm{S} 3$

Fig. 11 Load-strain curves of each specimen

To further analyze the stress state of the CFST keys, we calculated the principal stress based on the strains measured by the strain rosettes $\mathrm{H} 1$ and $\mathrm{H} 2$ on CFST keys of specimens S1 and S2. The load-principal stress curves are drawn and shown in Fig. 12. It can be seen from Fig. 12 that at the same vertical load, for both specimens S1 and S3, the principal stress at the center of the side of the upper CFST key was smaller than that of the lower one.For example, when the vertical load was $400 \mathrm{kN}$, the principal stress at the center of the upper steel tube was about $300 \%$ and $120 \%$ higher than that of the lower one for specimens S1 and S2, respectively. This indicates that the upper steel tube and the lower steel tube did not yield simultaneously under the same vertical load. This maybe because the lower part of the specimen was consolidated, while the upper part was unconstrained. Although the resultant force line of the upper load and the lower bearing resilience passed through the CFST center, the upper and lower restraints were not horizontally symmetric. When the principal stress was the same, specimen S1 had a larger vertical load difference between the upper part and lower part of the steel tube, compared with that of specimen S2. For example, when the principal stress was $200 \mathrm{kN}$, the corresponding vertical load differences between the upper and lower parts of steel tubes were $490 \mathrm{kN}$ and $250 \mathrm{kN}$ for specimens S1 and S2, respectively, which indicates that placing reinforced concrete block could make the stress of the upper and lower CFST keys more evenly.

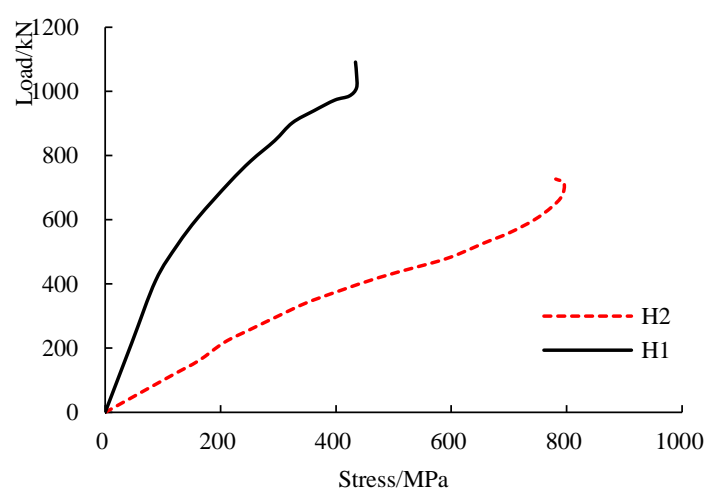

(a) Principal stress calculated from strain gauge rosettes on specimen S1

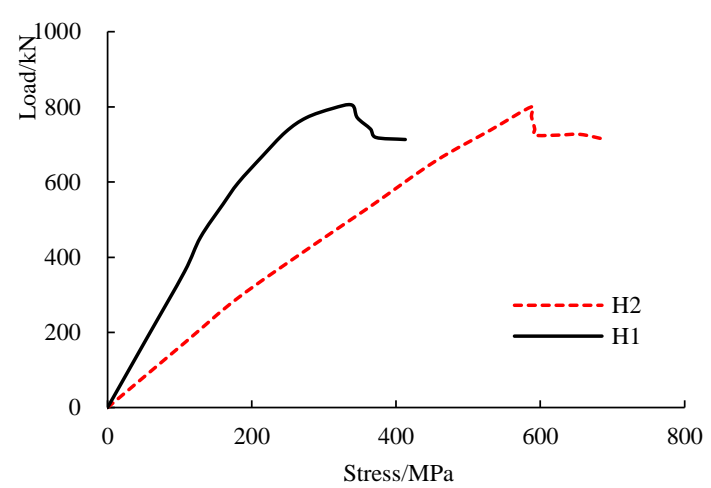

(b) Principal stress calculated from strain gauge rosettes on specimen S1

Fig. 12 Principal stress calculated from strain gauge rosettes on specimens S1 and S2

\subsubsection{Analysis of strain or stress of the steel tubes and steel bars of specimen} S4

(1) Analysis of strain of steel bars.

Because some of the steel strain gauges were damaged during the production of the specimen, only two sets of horizontal strain gauges and two sets of vertical strain gauges were selected to analyze the force behavior of the steel bars in the horizontal and vertical directions. The load-strain curves are shown in Fig. 13.

Fig.13(a) and Fig.13(b) are the curves of strain and vertical load as measured by strain gauges S1, S2, S3, S7, S8, and S9 which are shown in Fig.3. As can be seen from these two figures, for the same horizontal steel bars, the ones that were close to one end of the CFST keys (S1 and S7, referred to as the proximal end) received the stress lastly; the middle part of the steel bar (S2 and S8) was the first to be stressed; and the steel bar that was away from the end of CFST keys (S3 and S9, referred to as the distal end) was stressed next. The middle and distal end of the steel bar yielded while the proximal end did not yield. This result shows that when shear was transmitted through the CFST keys in the horizontal direction, the middle part of the steel bar was firstly stressed, then the distal end, and finally the proximal end, which is consistent with the development of the cracks shown in Fig. 10.

Fig.13 (c) and Fig.13 (d) are the curves of strain and vertical load measured by strain gauges S1, S10, S16, S2, S8, and S17 which are shown in Fig.3. As can be seen from Fig.13 (c), for the steel bars placed in the vertical direction, the lower part of the steel bars (S16) was stressed firstly, then, the middle part (S10), and lastly, the upper part (S1). Only the area measured by S16 exceeded the yield strain. Fig.13 (d) shows that the loading process of the steel bar was opposite to that illustrated in Fig.13 (c). The upper part of the steel bar (S2) was stressed firstly, then, the middle part (S8), and lastly, the lower part (S17) is the last. Even the area measured by S17 showed some effect of compressive strain. These phenomena are also consistent with the crack development on the walls shown in Fig.10(c) and Fig.10(d), in which the cracks were distributed in the middle and upper parts, and the oblique cracks appeared in the lower right part when the ultimate load was reached. These results show how the CFST keys transmitted shear in the vertical direction. The steel bar that was on the lower side of the CFST keys was pressed first. When the steel bar was away from the CFST keys, its upper part was stressed first. 


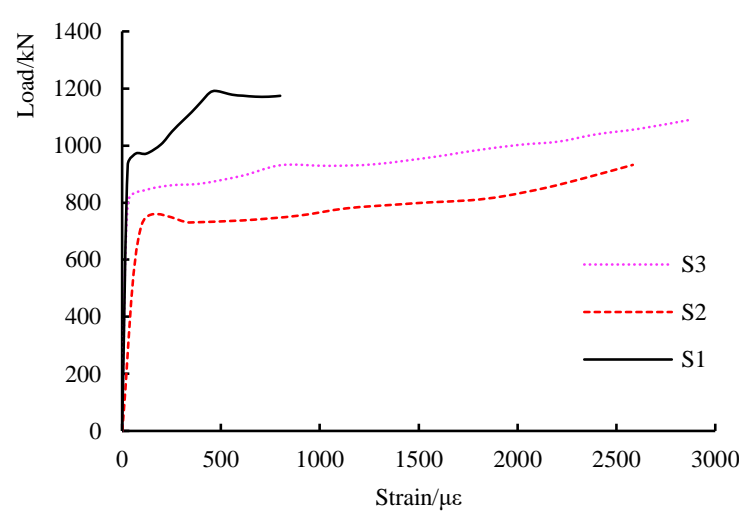

(a) Load-strain relationship curves measured by $\mathrm{S} 1, \mathrm{~S} 2$, and S3

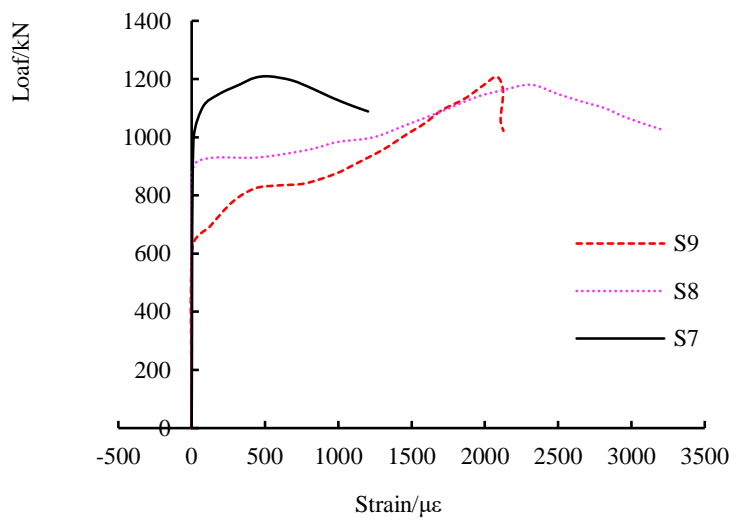

(b)Load-strain relationship curves measured by S7, S8 and S9

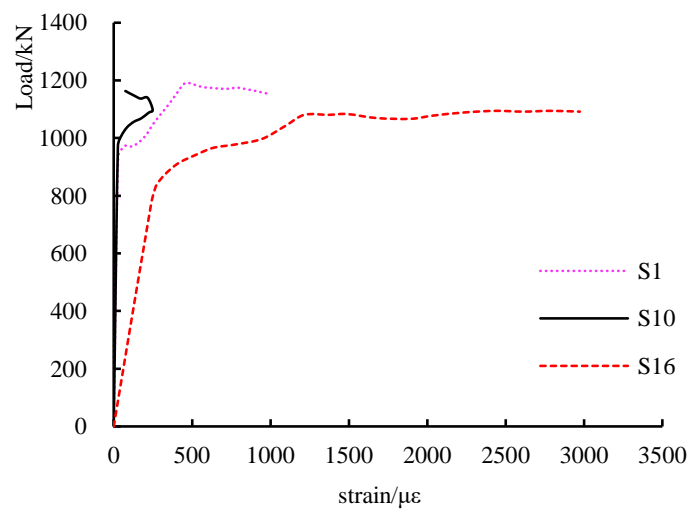

(c) Load-strain relationship curves measured by S1, S10, and S16

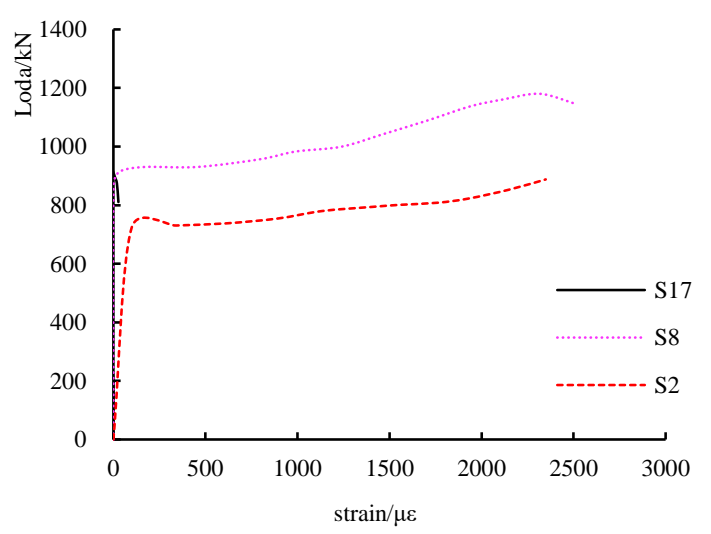

(d) Load-strain relationship curves measured by S2, S8, and S17

Fig. 13 Load-strain relationship curves of the steel bars

(2) Stress and strain analysis of the steel tubes

Fig.14 shows load-strain relationship curves of specimen S4 at the test areas as specified in Fig.7. It can be observed that the strain of the steel tube was less than 800 , indicating that after the steel tube was strengthened, the upper surface steel place and the lower surface steel plate of the CFST keys were not yielded. Fig.15 shows load-principle stress relationship curves of specimen S4 in the center of the side steel plate of CFST keys. The principle stress is calculated from the strain measured by GH1 and GH2. It can be seen that the stress at the center of the side steel plate of CFST keys exceeded the yield stress. This shows that although the steel plate of the CFST keys was reinforced, the center part of the side steel plate was still yielded.

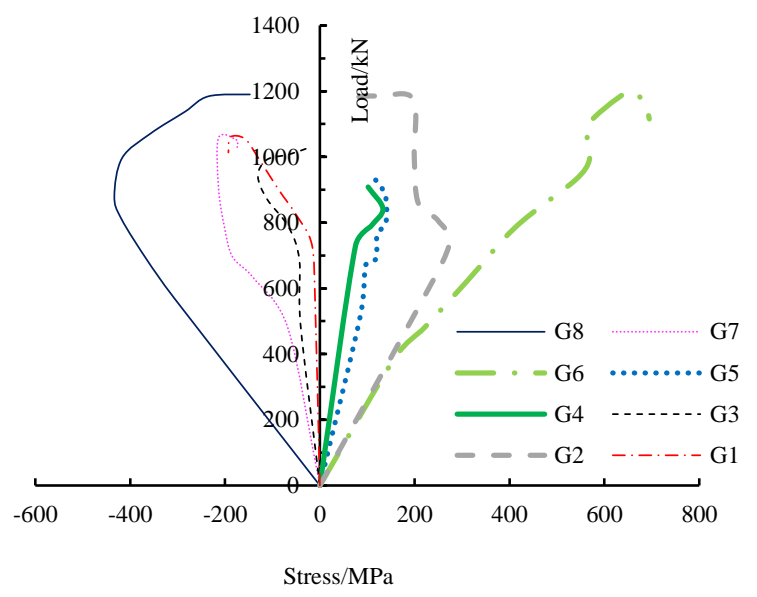

Fig. 14 Load-strain curves of the steel tube of specimen S4

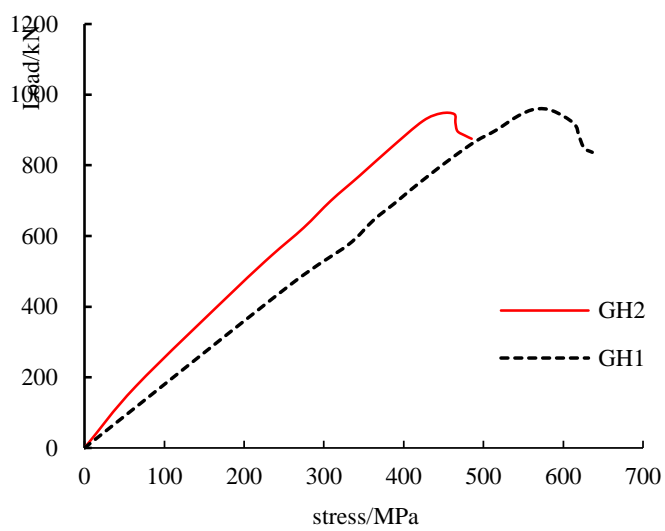

Fig. 15 Load-stress curves of the steel tube of specimen S4

\section{Analysis of Horizontal displacement between wall and column}

Fig.16 shows a vertical load-horizontal displacement curves of specimens $\mathrm{S} 1$ to $\mathrm{S} 4$, where the horizontal displacement was measured by displacement gauges W1 and W2 whose positions are shown in Fig.4(b), Fig.4(c), and Fig.7(a). It can be seen from Fig.16 that the displacements measured by W1 and W2 were small for the specimens and the maximum values were less than $9 \mathrm{~mm}$. These results indicate that the test device basically satisfied the requirement of vertical symmetry.

The displacements measured by W2 for the specimen were larger than those measured by W1 with smaller differences at the elastic stages and relatively larger differences at the inelastic stages. Specimens S3 had the smallest difference, with a maximum difference less than $0.6 \mathrm{~mm}$. The differences between the specimens that were connected by the CFST keys were relatively larger, and the maximum difference was $7.09 \mathrm{~mm}$. This shows that for the walls and columns connected by the CFST keys, when the shear was applied, the relative displacement between the walls and columns may be relatively large in the horizontal direction. This relatively large deviation is mainly due to the large inelastic deformation occurring in the inelastic stage of the CFST keys, which breaks the symmetry. 


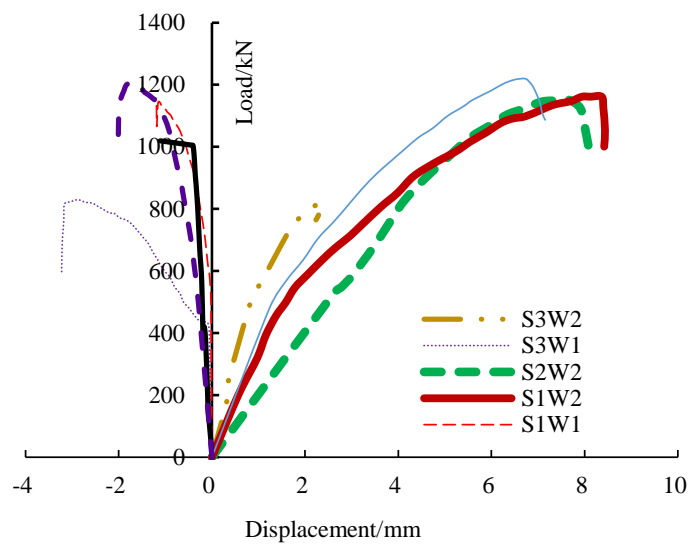

Fig. 16 Load-horizontal displacement curves measured by displacement meter W1 and W2

\section{Simplified calculation formula for shear bearing capacity}

The total shear bearing capacity of the CFST keys with the reinforced concrete block between them is composed of two parts: One is the shear capacity of the CFST keys, and the other is the compressive bearing capacity of the reinforced concrete block. Regarding the shear capacity of CFST keys, the calculation formulas adopted by the Chinese and American codes are simple, that is, only considering the shear strength of steel tubes and ignoring the role of concrete (ANSI/AISC 360-05[32], CECS 159:2004[33]). Considering that the damage form of the reinforced concrete block before the overall structure failure is close to the damage form of the member under axial compression, we adopted the calculation formula of the axial bearing capacity as a simplified formula to calculate the bearing capacity of the reinforced concrete blocks.Therefore, the simplified calculation formulacan be obtained as follows:

\section{$V=2 n \cdot t_{s} \cdot h_{s} \cdot f_{v}+(n-1) f_{c} b_{c} h_{c}(1)$}

Where $V$ is thetotal shear bearing capacity of the CFST keys with the reinforced concrete block between them; $n$ is the number of CFST keys; $t_{\mathrm{s}}$ and $h_{\mathrm{s}}$ are the thickness and height of rectangular steel tube, respectively; $f_{\mathrm{v}}$ is the shear yield strength of steel; $f_{\mathrm{c}}, b_{\mathrm{c}}$, and $h_{\mathrm{c}}$ are the compressive strength, section width, and section height of the reinforced concrete block, respectively.

The shear capacity of specimens S2 and S4 were calculated to be $993 \mathrm{kN}$ and $1507 \mathrm{kN}$, respectively, which were $1.3 \%$ and $65 \%$ higher than the yield load of specimen S2 and specimen S4, respectively. The calculated results were in line with that for specimen S2; however, the calculated results deviated greatly from that for specimen S4. This is mainly because the equation assumes that the steel plate section all meets the yield strength $f_{\mathrm{v}}$ of the shear key, while specimen S4 had seen wall damage mostly and only a small part of the steel plate reached the yield strength. This shows that the equation can be used to estimate the shear capacity of the connection.

\section{Conclusions}

This paper describes the shear test of the CFST keysconnected shear wall and columns in the frame-shear wall structure and presents the test results systematically.A practical method for wall and column connection isproposed ,which shows good mechanical properties. We also established the simplified calculation formulaforthetotal shear bearing capacity ofthis connection.These works provide a powerful basis for exploring the application of composite structural members to prefabricated concrete structures. The main findings of this study are as follows:

(1)With regard to the wall and column connection by the CFST keys with reinforced concrete blocks placed between them, its bearing capacity and ductility were better than the cast-in-place structure, while the initial stiffness was the same as the cast-in-place structure.It shows good engineering feasibility.

(2)The wall-column connection method of the CFST keys with reinforced concrete blocks showed good seismic performance. In the elastic stage, the reinforced concrete blocks were intact and the structural rigidity was almost equal to the cast-in-place structure. This connection can meet the seismic fortification target of "no damage under small earthquakes." After yielding, the reinforced concrete blocks were damaged, and the structural rigidity decreased. The CFST keys and reinforced concrete blocks exerted constraints on each other, enabling a high bearing capacity and ductility. These characteristics can help meet the seismic fortification target of "no collapse in major earthquakes."

(3) When designing the connection of wall and column by the CFST keys with reinforced concrete blocks placed between them, we should control the strength of the CFST keys properly. When the CFST keys are too strong in design, the damage to the reinforced concrete block will increase and the structural damage will be transmitted to the wall, leading to the reduction on bearing capacity of the whole structure.

\section{Acknowledgement}

This project was completed with the support of the Thirteenth National Key-point Research and Invention Program (2017YFC0703805) and Scientific Research Fund Project of Liaoning Provincial Department of Education(LNQN201907).

\section{References}

[1] Yuan S.M., "Experimental Research on Frame-shear Wall Structure Based on differen Column-Wall Connection Ways ", Master's Thesis, Shenyang Jianzhu University,Shenyang, China, 2016.

[2] Si X.B., "Research on the shear performance of prefabricated connection", Master's Thesis, Shenyang Jianzhu University,Shenyang, China, 2017.

[3] Restrepo J.I., Park R., and Buchanan A.H., "Tests on connections of earthquake resisting precast reinforced concrete perimeter frames of buildings", PCI Journal, 40(4), 44-61, 1995.

[4] Li N., Zhang J.C., CHU X.F. and LIU B., "Experimental study on seismic behavior of pre-cast concrete beam-column sub-assemblage with cast-in-situ monolithic joint", Engineering Mechanics, 26(S1), 41-44, 2009.

[5] Li S.D., "Experimental study on seismic performance of precast concrete columns and joints", Master's Thesis, Harbin Institute of Technology, Harbin, China, 2013.

[6] Alcocer S.M., Carranza R., Perez-Navarrete D.,et al., "Seismic tests of Beam-to-Column Connections in a precast concrete frame", PCI Journal, 47(3), 70-89, 2002.

[7] Guan D.Z., Guo Z.X., Yu J.B., et al., "Structural measures and experimental study of precas concrete joints of anchored prestressing strands in frames" Journal of Zhejiang University(Engineering Science), 50(2), 282-291, 2016.

[8] Zhao Y., Li Y.B., Bi Q., et al., "Experimental investigation on seismic performances of knee joints for monolithic precast concrete frame", Journal of Tongji University(Natural Science), $47(5), 600-608,2019$.

[9] Lu X.L., Wang L., Wang D., et al., "An innovative joint connecting beam for precast concrete shear wall structures", Structural Concrete, 17(6), 972-986, 2016.

[10] Chen J.W. and Su Y.P., "Prefabricated concrete shear wall structure and its connecting technology", World Earthquake Engineering, 29(1), 38-48, 2013.

[11] Sun J.,QiuH.X.,Lu Y., et al., "Experimental study of lateral load behavior of H-shaped precast reinforced concrete shear walls with bolted steel connections", The Structural Design of Tall and Special Buildings, 2019, https://doi.org/10.1002/tal.1663.

[12] Song G. and Wang Y., "Low frequency cyclic loading tests of L-shaped precast sandwich insulation shear wall", Building Structure, 46(10), 20-23, 2016

[13] Lu Z., Wang Y., Li J.B., et al., "Experimental study on seismic performance of L-shaped insulated concrete sandwich shear wall with a horizontal seam", The Structural Design of Tall and Special Buildings, 28(1), 2019.

[14] JGJ101-96, Specification of testing methods for earthquake resistant building, Ministry of Housing and Urban-Rural Development of the People's Republic of China, Beijing, 1996.

[15] Smith B.J., Kurama Y. C., and McGinnis J, "Behavior of Precast Concrete Shear Walls for Seismic Regions: Comparison of Hybrid and Emulative Specimens", Journal of Structural Engineering, 139(11), 1917-1927, 2013.

[16] Pekau O. A. and Hum D., "Seismic response of friction jointed precast panel shear walls", PCI Journal, 36(2), 56-71, 1991.

[17] Soudki K. A., Rizkalla S. H. and LeBlanc B., "Horizontal connections for precast concrete shear walls subjected to cyclic deformations part 1: Mild steel connections", PCI Journal, 40(4), 78-96, 1995.

[18] Li J.B., Fan Q.Q., Lu Z., et al., "Experimental study on seismic performance of T-shaped partly precast reinforced concrete shear wall with grouting sleeves", Struct Design Tall Spec Build, e1632, 2019, https://doi.org/10.1002/tal.1632.

[19] Soudki K. A., Rizkalla S. H., and Daikiw R. W., " Horizontal connections for precast concrete shear walls subjected to cyclic deformations part 2: Prestressed connections", PCI Journal, 40(5), 82-96, 1995

[20] Wang Z., "Study on Mechanical Properties and Design Methods of the Equivalent Replacement Rebar Pre-Cast Concrete Coupling Beams", Master's Thesis, Shenyang Jianzhu University,Shenyang, China, 2016

[21] Gao J., "Study on performance of concrete filled steel tubular composite keyway connection in assembled frame-shear structures",Master's Thesis, Shenyang Jianzhu University,Shenyang, China, 2019.

[22] Liang Q.C., "Study on mechanical properties and design method of steel-connected concrete Beams", Master's Thesis, Shenyang Jianzhu University,Shenyang, China, 2019.

[23] Mo C., "Study on seismic performance of fully precast frame-shear wall structure", Master' s Thesis, Southeast University, Nanjing, China, 2017.

[24] Ma J.W., "Study on seismic behavior of the new full precast concrete shear-wall frame stru ctures", Ph.D. Dissertation, Southeast University, Nanjing, China, 2018

[25] Wu D.Y., LIANG S.T., GUO Z.X., et al., "Experimental study on grouted connecting precast shear-wall spatial structural model", Journal of Building Structures, DOI: 10.1 4006/j.jzjgxb.2018.0426.

[26] Wu Y.H., YUE Q.R., ZENG B., et al., "Research on seismic design of prefabricated e nclosure wall for industrial buildings", Industrial Construction, 47 (4) , 166-173, 2017.

[27] Bin L S and LEI D., "The development of prefabricated concrete structures", 20142 n d International Conference on Mechanical Structures and Smart Materials, Malaysia, 81 $-84,2014$.

[28] Ming L. and YANG Z. H., "The Connection Form of The Beam and Column in Prefa bricated Concrete Structure", 4th International Conference on Civil Engineering,Archite cture and Building Materials(CEABM2014), Haikou, 818-821, 2014. 
[29] GB50017-2017, Standard for design of steel structures, Ministry of Construction of Ch ina, Beijing, China, 2017.

[30] GB50010-2010, Code for design of concrete structures, Ministry of Construction of Ch ina, Beijing, China, 2010.

[31] GB /T 50152-2012, Standard for test method of concrete structures, Ministry of Construction of China, Beijing, China, 2012

[32] Li Z.H., PENG Z.H., QI Y.H., et al., "Full-scale experimental study on seismic behaviors of plasticity controllable steel joint of prefabricated RC beam column", Journal of Building Structures, 40(10), 43-50, 2019.

[33] ANSI/AISC 360-05, Specification for Structural Steel Buildings, American Institute of Construction, Chicago, USA, 2005.

[34] CECS 159:2004, Technical Specification for Structures with Concrete-filled Rectangular Steel Tube Members, China Association for Engineering Construction Standardization, Shanghai, China, 2004. 